\title{
EDUCAÇÃO EM SAÚDE: PONDERAÇÕES DE UM ITINERÁRIO FREIRIANO
}

\section{HEALTH EDUCATION: CONSIDERATION OF A FREIRIAN ITINERARY}

\author{
Isabel Cristina Bohn Vieira \\ Universidade do Vale do Itajaí - UNIVALI \\ isabelbohnvieira@gmail.com
}

Eduardo Augusto Werneck Ribeiro Instituto Federal Catarinense - IFC eduardo.ribeiro@ifc.edu.br

Ivonete Teresinha Schülter Buss Heidemann Universidade Federal de Santa Catarina - UFSC ivoneteheidenan@gmail.com

\begin{abstract}
RESUMO
A presente pesquisa tem como objeto de estudo a investigação temática "Educação em Saúde", a partir da metodologia de Círculo de Cultura de Freire, abarcando os profissionais da Saúde e da Educação Básica de Ensino. O objetivo da proposta consistiu em desvelar mediações que condicionem a dialogicidade intersetorial e a aprendizagem significativa acerca de respostas que levem a intervenções promotoras de saúde em territórios de ação desses profissionais. Consolidando a pesquisa, o trabalho foi dividido em três momentos de dialogicidade e reflexão: Temas Geradores, Codificação/ Descodificação e Desvelamento Crítico. Os resultados obtidos apontaram que, adentrar a intersetorialidade com a temática em questão permitiu promover a elucidação de conceitos até então desconhecidos entre os participantes, bem como sua (re)significação frente ao processo dialógico. Também, sinalizaram que recursos midiáticos aplicados em pesquisa participativa, são doravante contributivos. Salienta-se que, buscar a integração das diferentes áreas de conhecimento com vistas a autonomia no conjunto das ciências, implica reconhecer o território como forma indissociável a reprodução do trabalho e da dimensão histórica dos grupos socais. De fato, esta etapa futura mostra-se como um desafio a ser dirimido.
\end{abstract}

Palavras-chave: Educação em Saúde. Itinerário Freiriano. Intersetorialidade.

\begin{abstract}
This research has as its object of study the thematic investigation "Education in Health", based on the methodology of Freire's Culture Circle, encompassing Health and Basic Education professionals. The purpose of the proposal was to unveil mediations that condition intersectoral dialogicity and meaningful learning about responses that lead to healthpromoting interventions in these professionals areas of action. Consolidating the research, the work was divided into three moments of dialogicity and reflection: Generating Themes, Coding / Decoding and Critical Unveiling. The results obtained pointed out that, entering the intersectoriality with the theme in question allowed to promote the elucidation of concepts hitherto unknown among the participants, as well as their (re) significance in relation to the dialogical process. Also, they signaled that media resources applied in participatory research, are henceforth contributory. It should be noted that, seeking the integration of different areas of knowledge with a view to autonomy in the set of sciences, implies recognizing the territory as an inseparable way the reproduction of work and the historical dimension of social groups. In fact, this future stage presents itself as a challenge to be solved.
\end{abstract}

Keywords: Health Education. Freirian Itinerary. Intersectoriality.

Recebido em: 03/11/2021

Aceito para publicação em: 12/02/2021. 


\section{INTRODUÇÃO}

No Brasil, as ações educativas em saúde estiveram presentes nos discursos oficiais a partir de 1889 , época da Primeira República, centradas no ensino de comportamentos e hábitos considerados saudáveis. No princípio do século XX, na concepção higienista-eugenista, a educação em saúde visava o desenvolvimento de uma "raça" sadia e produtiva, a partir da observação, exame, controle e disciplina na infância. Por conseguinte, as práticas pedagógicas eram centradas em ações individualistas, focadas na mudança de comportamentos e atitudes, sem muitas vezes considerar as inúmeras condições de vida do território no qual os indivíduos estavam inseridos (ALBUQUERQUE et al., 2017).

Saúde e educação são constantemente assomadas quando a questão gira em torno das condições de vida de uma população em um determinado território. A interação entre elas, constitui um caminho importante na construção e conquista pelo bem-estar físico, mental e social do indivíduo, ou seja, seu estado positivo de saúde (CANGUILHEM, 2012). A elaboração de práticas de pesquisa relacionadas a essa interação é um grande desafio frente a fragmentação entre os setores envolvidos.

O desenvolvimento de pesquisas participativas proporciona um grande avanço no envolvimento da sociedade através da participação dos sujeitos, verdadeiros autores e condutores de pesquisas. Ao ter o diálogo como ferramenta-chave na condução e efetivação de seus passos, a pesquisa participativa se caracteriza por compreender e valorizar diferentes conhecimentos, dando destaque a uma ciência ética e politicamente comprometida com a transformação social, que, por suposto, converge para a efetivação da intersetorialidade entre saúde e educação (HEIDEMANN et al., 2010).

Partindo da premissa dialógica e participativa, o brasileiro Paulo Reglus Neves Freire, reconhecido como o patrono da educação brasileira, sinalizou a incapacidade das pessoas de se autoconhecerem como sujeitos de suas vidas, o que os limitava ainda mais em vislumbrar alguma possibilidade de mudança daquela realidade e; além disso, percebeu que esses (oprimidos) eram dominados por pessoas que não Ihes reconheciam como seres humanos integrais, apenas lhes davam valor por os servirem e, assim alcançarem os seus (dos opressores) próprios interesses. Freire, iniciou sua caminhada como educador com um olhar aguçado para as reais necessidades desses sujeitos e desenvolveu o "Método Paulo Freire" de ensinar, de empoderar, valorizando os saberes prévios existentes nesses indivíduos. Seus ensinamentos ecoaram em todo o mundo e trouxeram à luz uma compreensão para a quebra dos paradigmas existentes (HEIDEMANN et al., 2017).

A perspectiva Freiriana no que se refere a dialogicidade e a problematização como principais categorias para uma educação humanizadora, libertadora e transformadora, sinaliza que por meio do diálogo é possível olhar o mundo e a sociedade como processo, como algo em construção, como realidade inacabada e em constante transformação. Além disso, Freire (1981), indica que a problematização dos processos significativos ou temas geradores "[...] não se encontram nos homens isolados da realidade, nem tampouco na realidade separada dos homens. Só pode ser compreendido nas relações homensmundo" (Idem, p.114).

Nesse ínterim, o modus operandi de Paulo Freire é uma opção metodológica que utiliza como estratégia - Círculo de Cultura, no qual pesquisador e pesquisando realizam reflexões e discussões sobre a realidade e coletivamente procuram desvelar e identificar as possibilidades de intervenções sobre um tema. Os participantes, mediante um processo de ação-reflexão-ação, são levados a se perceberem como autores de suas histórias e com isso se conscientizam e se fortalecem para modificar as suas práticas. O Círculo de Cultura é um termo criado por Freire, representado por um espaço dinâmico de aprendizagem, troca de saberes e (re)conhecimento do ser humano. Este, representa uma situação/problema de situações reais, que levam à reflexão da própria realidade, para na sequência, descodificá-la e reconhecê-la (HEIDEMANN et al., 2017).

Destarte, a presente pesquisa é segmento de projeto de tese que tem como objeto de estudo a investigação temática "Educação em Saúde", a partir da metodologia de Círculo de Cultura de Freire, abarcando o profissionais da Saúde e da Educação Básica de Ensino, com o objetivo de desvelar mediações que condicionem a dialogicidade intersetorial e a aprendizagem significativa acerca de respostas que levem a intervenções promotoras de saúde e não higienista-eugenista em territórios de ação desses profissionais.

Para tanto, nesta esteira, à luz da educação em saúde, sob a ótica Freiriana e constituinte do eixo temático "Território, ambiente e saúde", este trabalho é estruturado em cinco tópicos, sendo os dois primeiros apresentados como fundamentação teórica da investigação temática, intitulados "Educação em Saúde" e "Itinerário Freiriano"; o terceiro, abordando os aspectos metodológicos da pesquisa e, por

$\begin{array}{llllll}\text { Hygeia Uberlândia - MG } & \text { Edição especial: X GeoSaude } & \text { Fev./2022 } & \text { p. 1-11 Página } 2\end{array}$


fim, o quarto no qual consta os desdobramentos da aplicação metodológica do Círculo de Cultura de Freire, para sua posterior reflexão nas considerações finais.

\section{EDUCAÇÃO EM SAÚDE}

O termo educação em saúde vem sendo utilizado desde as primeiras décadas do século $X X$ com a expansão da medicina preventiva para algumas regiões do país. A partir da década de 1940, o Serviço Especial de Saúde Pública (SESP), apresentava estratégias de educação em saúde autoritárias, tecnicistas e biologicistas, em que as classes populares eram vistas e tratadas como passivas e incapazes de iniciativas próprias. As ações do Estado se davam por meio das chamadas campanhas sanitárias e outras formas de educação em saúde eram caracterizadas por ações verticais de caráter informativo com o intuito de transformar hábitos de vida, colocando o indivíduo como o responsável pela sua saúde (FALKENBERG et al., 2014).

Com a promulgação da Constituição Federal de 1988, criação do Sistema Único de Saúde (SUS) essas ações tiveram novos vieses. O SUS é considerado uma grande conquista social bem como, um dos maiores sistemas públicos de saúde mundial, sendo o único que garante a assistência integral e totalmente gratuita para a totalidade da população. O sistema é composto pelas ações e serviços de saúde ofertados pelas esferas públicas federais, estaduais e municipais (BRASIL, 2000; SOUZA, 2002).

Desde a sua criação e posterior implementação, diversas políticas públicas, ações e programas de saúde têm contribuído para o fortalecimento do SUS, através da promoção de saúde e educação em saúde, descentralizando assim, o modelo curativista e biológico até então preconizado. Conforme o Ministério da Saúde (MS), a educação em saúde pode ser definida como:

Processo educativo de construção de conhecimentos em saúde que visa à apropriação temática pela população [...]. Conjunto de práticas do setor que contribui para aumentar a autonomia das pessoas no seu cuidado e no debate com os profissionais e os gestores a fim de alcançar uma atenção de saúde de acordo com suas necessidades (BRASIL, 2006).

As práticas de educação em saúde envolvem três segmentos de atores prioritários: os profissionais de saúde que valorizem a prevenção e a promoção de saúde; os gestores que apoiem esses profissionais; e a população que necessita construir seus conhecimentos e aumentar sua autonomia nos cuidados, individual e coletivamente. Embora a definição do MS apresente elementos que pressupõem essa interação entre os três segmentos das estratégias utilizadas para o desenvolvimento desse processo, ainda existe grande distância entre retórica e prática.

De acordo com Becker e Heidemann (2020), a educação em saúde é um dos principais eixos estratégicos para a promoção da saúde. As concepções sobre promoção de saúde foram introduzidas no Brasil através da VIII Conferência Nacional de Saúde em $1986 \mathrm{com}$ a Carta de Ottawa. E, de acordo com Carvalho (2015) a Promoção de saúde pode ser definida como:

[...] um conjunto de estratégias e formas de produzir saúde, no âmbito individual e coletivo, caracterizando-se pela articulação e cooperação intra e intersetorial [...] buscando articular suas ações com as demais redes de proteção social, com ampla participação e controle social" (CARVALHO, 2015).

A intersetorialidade é uma questão-chave para os setores educação, saúde e assistência social desenvolverem ações de promoção de saúde. Dentre os níveis de atenção do SUS para o desenvolvimento dessas ações, destaca-se a Atenção Primária à Saúde (APS), desenvolvida com o mais alto grau de descentralização e capilaridade (BECKER; HEIDEMANN, 2020).

Neste cerne, o governo Federal Brasileiro instituiu o Programa Saúde na Escola (PSE) através do Decreto № 6.286/2007, sendo este, implementado pela APS que integra uma política de governo voltada à intersetorialidade e que atende aos princípios e diretrizes do Sistema Único de Saúde (SUS):

[...] integralidade, equidade, universalidade, descentralização e participação social. O PSE, propõe um desenho de política de educação em saúde como parte de uma formação ampla para a cidadania e promotora da articulação de saberes com a participação de alunos, pais, comunidade escolar e sociedade em geral ao tratar a saúde e educação de forma integral (BRASIL, 2007).

A escola, nesse contexto, é identificada como espaço no qual tradicionalmente ocorrem ações e práticas educativas em saúde que atendem aos preceitos do SUS. De acordo com Freire (1981, p.101)

$\begin{array}{llllll}\text { Hygeia Uberlândia - MG } & \text { Edição especial: X GeoSaude } & \text { Fev./2022 } & \text { p. 1-11 Página } 3\end{array}$


"é na realidade mediatizadora, na consciência que dela tenhamos educadores e povo, que iremos buscar o conteúdo programático da educação".

O autor supracitado, preconiza que o processo de ensino e aprendizagem não é significativo se fragmentado da realidade do educando e não dialógico. Rodrigues; Pereira e Mohr (2020) pontam que mudanças em currículos na educação, dadas por imposição vertical e desarticuladas de outras iniciativas, historicamente fracassam. Tendo isto posto, infere-se novamente a intersetorialidade como caminho para a educação em saúde.

No campo Educacional, a fim de superar as iniquidades sociais e cognitivas, visando estruturar e orientar o processo de ensino e aprendizagem na Educação Básica e, buscando o desenvolvimento na integralidade, biológico, psicológico e social do educando, o governo Federal Brasileiro deliberou alguns documentos norteadores do ensino, que se efetivaram ao longo da história até o atual momento. Hoje, a Base Nacional Comum Curricular (BNCC) é um documento de caráter normativo que define o conjunto orgânico e progressivo de aprendizagens essenciais que todos os alunos devem desenvolver ao longo das etapas e modalidades da Educação Básica. A abordagem dos Temas Contemporâneos Transversais (TCTs), incluso no documento da BNCC, propõem assegurar os preceitos supracitados para os educandos, fazendo-se de aplicação obrigatória no currículo nas redes de ensino em todos os objetos de conhecimento (disciplinas). Este, aponta que:

[...] cabe aos sistemas e redes de ensino. Assim como as escolas, em suas respectivas esferas de autonomia e competência, incorporar aos currículos e às propostas pedagógicas a abordagem de temas contemporâneos que afetam a vida humana em escala local, regional e global, preferencialmente de forma transversal e integradora (BRASIL, 2017, p. 19).

Todavia, dentre as seis macroáreas articuladas pelo documento TCTs, a macroárea "Saúde" está pautada no Parecer CNE/CEB № 11/2010 - Diretrizes Curriculares Nacionais para o Ensino Fundamental de 9 (nove) anos -, na Resolução CNE/CEB № 7/2010 - Fixa Diretrizes Curriculares Nacionais para o Ensino Fundamental de 9 (nove) anos - e no Decreto № 6.286/2007 - Institui o Programa Saúde na Escola - PSE, e dá outras providências - , ou seja, o processo de ensino e aprendizagem de Educação em Saúde na escola está estruturado no último documento e, este exclui a rede privada de ensino, fato controverso a proposta da BNCC e as diretrizes do SUS quanto a equidade (BRASIL, 2018).

De acordo com o Decreto № 6.286/2007 o PSE, "constitui estratégia para a integração e a articulação permanente entre as políticas e ações de educação e de saúde, com a participação da comunidade escolar, envolvendo as equipes de saúde da família e da educação básica". O referido programa é essencialmente intersetorial, mas muitas vezes não acontece de forma efetiva pela falta de complementação da legislação vigente e/ou carência de estratégias didático-pedagógicas que atendam os diferentes níveis de ensino ou diferentes esferas do saber, como sinalizadas pelo psicólogo Howard Gardner, ao desvelar a teoria das inteligências múltiplas (GARNER, 1992). Assim, apesar de propor o diálogo (em tese), esta lacuna na orientação traz um efeito contrário ao esperado por não haver uma diretriz comum, pois os setores estão propícios a sugestões e intencionalidades diferentes, o que pode resultar disputas, até mesmo, a sobreposição do interesse de um setor sobre o outro, fadando o PSE ao insucesso.

Tendo isto posto, emerge a necessidade da dialogicidade entre os setores para o desenvolvimento de atividades de Educação em Saúde, bem como para o reconhecimento sobre documentos que norteiam e garantem a efetivação desse processo. A educação em saúde como processo político pedagógico requer o desenvolvimento de um pensar crítico e reflexivo, permitindo trabalhar a realidade e propor ações transformadoras que levem o indivíduo à sua autonomia e emancipação como sujeito histórico e social, capaz de propor e opinar nas decisões de saúde para cuidar de si, de sua família e de sua coletividade (FALKENBERG et al., 2014).

Desvelar mediações que condicionam a dialogicidade e a aprendizagem significativa acerca de respostas que levem a intervenções no eixo da educação em saúde de forma intersetorial, ainda é um desafio para os profissionais envolvidos no processo. Conforme Freire (p. 79, 1981), "Ninguém educa ninguém, ninguém se educa a si mesmo, os homens se educam entre si, mediatizados pelo mundo". Somente rompendo conceitos arraigados conseguiremos aprender a ler a realidade para poder transformá-la, pensando assim em alternativas viáveis de educação em saúde, que configure promoção de saúde em sua integralidade de forma universal e equitativa em todo o território, o qual os sujeitos se encontram e se inter-relacionam.

$\begin{array}{lllll}\text { Hygeia Uberlândia - MG } & \text { Edição especial: X GeoSaude } & \text { Fev./2022 } & \text { p. 1-11 Página } 4\end{array}$




\section{ITINERÁRIO FREIRIANO}

O itinerário de pesquisa de Freire representa uma abordagem de pesquisa qualitativa participativa e com cunho libertador/emancipador. Os saberes de Paulo Freire têm sido estudados e utilizados por muitos pesquisadores de diferentes áreas de atuação. O Laboratório de Pesquisa em Enfermagem e Promoção da Saúde (LAPEPS), vinculado à Universidade Federal de Santa Catarina (UFSC), iniciou suas atividades em 1994 e, desde então, vem utilizando o referencial teórico metodológico freiriano em seus estudos (HEIDEMANN et al., 2017).

Paulo Freire, ao propor o itinerário de pesquisa, operacionalizando-o por meio dos Círculos de Cultura, não pensou na sua aplicabilidade na área da saúde como um método de pesquisa e/ou como um método orientador do processo de trabalho de pesquisa participativa. Todavia, as experiências do Grupo de Pesquisa LAPEPS, têm ratificado que essa metodologia contribui para os estudos e o trabalho em saúde, à medida que agrega um potencial pedagógico transformador e conscientizador aos participantes, sejam docentes, discentes, pesquisadores, profissionais da saúde ou usuários. Essa metodologia promove espaços de encontro entre as pessoas, rompendo com as barreiras hierárquicas do modelo biomédico, democratizando o saber em saúde, valorizando os cotidianos, as culturas e as formas de pensar e viver das famílias, grupos e coletividades (HEIDEMANN et al., 2017).

Conforme Costa et al., (2018):

No Círculo de Cultura, o pesquisador é considerado como mobilizador, mediador, ou moderador da ação-reflexão-ação, realizada pelos participantes. Nesse processo, é estabelecida a relação horizontal entre as pessoas que vivenciam o Círculo de Cultura, cuja liberdade para o diálogo instiga os sujeitos sociais para que se sintam sujeitos.

Congruente com o autor supracitado, esse método viabiliza a participação ativa de todos os envolvidos na pesquisa, sendo construído e ressignificado ao longo de toda a trajetória a dialógica, recíproca e verdadeiramente humana, através da intermediação de saberes e práticas impressos nas vivências e experiências dos grupos humanos, sejam eles profissionais ou populares. Ressalta-se que, na pesquisa participante, o pesquisador também é o pesquisado, e deve fazer parte de todo o processo de ação-reflexão-ação.

Freire, quando propôs em suas obras o seu itinerário de pesquisa, sinalizou que esse deveria ser amplamente divulgado e utilizado nos diversos campos do saber, e que o objetivo final da sua aplicação deveria ser a transformação da realidade dos participantes dos Círculos de Cultura. De acordo com pesquisa dos autores: Heidemann, Boehs, Wosny e Stulp (2010); Cunha, Backes, Heidemann (2012) Heidemann e Wosny (2014); Heidemann et al. (2017); Costa et al., (2018), os momentos que compõem o Itinerário Freiriano podem ser descritos como:

Círculo de Cultura: É formado por um grupo de pessoas que se reúne para discutir sobre o seu trabalho; a sua realidade e/ou; a sua vida familiar. O propósito do Círculo de Cultura é analisar a prática cotidiana e atuar de modo a provocar mudanças de atitude que reflitam na melhoria da realidade vivenciada.

Temas ou palavras geradoras: Esta etapa é definida como fase de investigação temática, cujos temas e palavras geradores são extraídos do universo cotidiano. A palavra geradora e formar outras palavras que possibilitem uma leitura não só linguística, mas também política da realidade. Este é o momento da definição dos problemas ou situações limites, da construção da educação e do pensamento crítico entre participantes e mediadores da pesquisa. A investigação temática se constitui essencialmente da consciência da realidade e da autoconsciência que dá início ao processo educativo libertador.

Codificação e Descodificação: A codificação abrange certos aspectos do problema que se quer estudar, permitindo conhecer alguns momentos do contexto concreto, sendo reveladas as contradições e apontadas as representações das situações vividas. Esta fase do método representa as situações existenciais, na qual as codificações oferecem diferentes possibilidades de análises na sua descodificação, não sendo frases prontas, mas objetos cognoscíveis que incitam a reflexão crítica de homens e mulheres sobre a realidade vivida. A descodificação é a análise crítica da situação vivida, um momento dialético em que os participantes passam a admirar, refletir sobre sua ação. Nesta fase, refazem seu poder reflexivo e se reconhecem como seres capazes de transformar o mundo e superar seus limites, despertando novos olhares sobre a sua realidade.

Desvelamento crítico: Esta etapa é o momento de reflexão que vai estimular a ação, isto é, o movimento necessário para que os participantes da pesquisa possam apreender/perceber, analisar

$\begin{array}{llllll}\text { Hygeia Uberlândia - MG } & \text { Edição especial: X GeoSaude } & \text { Fev./2022 } & \text { p. 1-11 Página } 5\end{array}$


fenômenos e processos e discutir como transformá-los. Por ser a fase da tomada de consciência do participante da situação real, ocorre o processo de ação-reflexão-ação para a superação das contradições da realidade vivida. Desta forma, o pesquisador deve ser o mediador deste processo, impulsionar o percorrer de um caminho para a democracia e possibilitar uma compreensão crítica da realidade utilizando-se de um diálogo franco e corajoso no decorrer de todo processo.

Acordante com a proposta supracitada, o esquema do itinerário de pesquisa de Paulo Freire, composto por momentos dialógicos, encontra-se representado na figura 1.

Figura 1 - Etapas do Itinerário Freiriano.

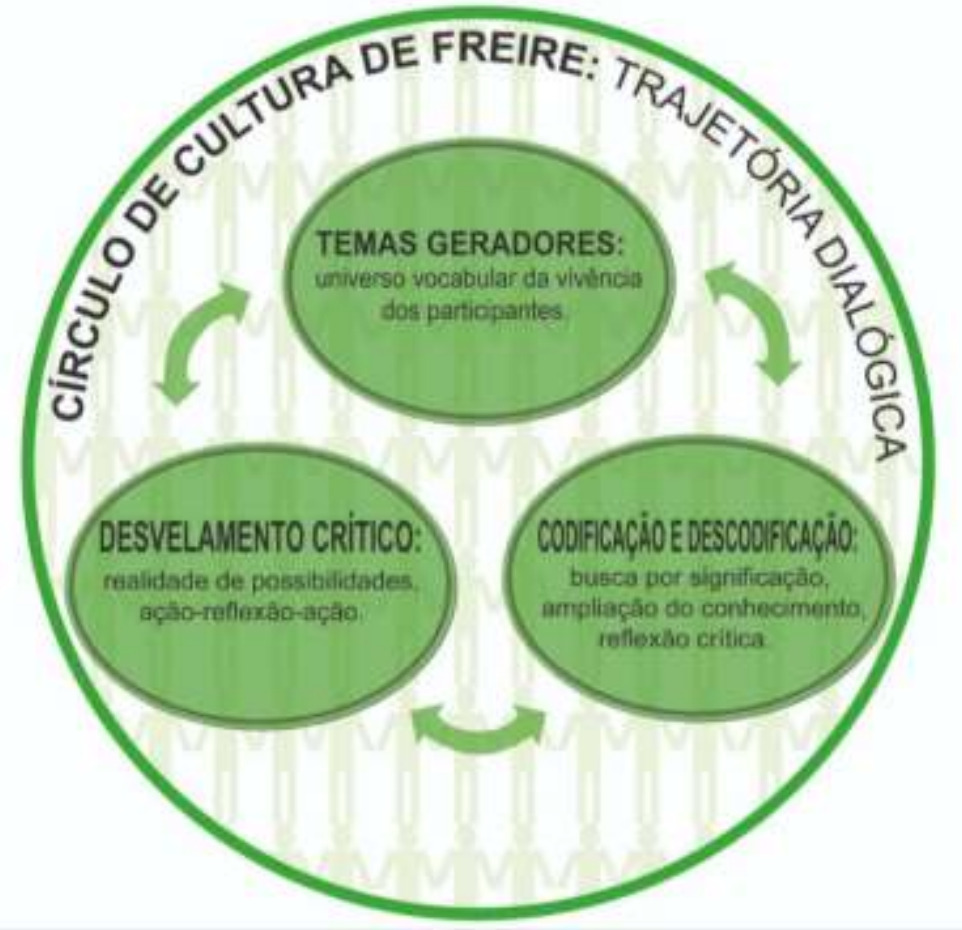

Fonte: Interpretação FREIRE (1981); (2013). Organizado pelos autores (2021).

Para mediar o debate em um Círculo de Cultura, procura-se dialogar sobre cada tema gerador e sugerese ao final da realização do itinerário freiriano, uma avaliação conjunta, com registro, entre o mediador e os participantes sobre a experiência vivenciada e das transformações percebidas por eles.

Nesta perspectiva de educação integral, dialógica e problematizadora, que a proposta do Círculo de acultura apresenta, as diferentes concepções para a pesquisa participativa, se perfazem, tornando a Educação em Saúde factível em sua práxis. Freire (2013, p. 25) alude que:

[...] educar e educar-se, na prática da liberdade, é tarefa daqueles que sabem que pouco sabem por isto sabem que sabem algo e podem assim chegar a saber mais em diálogo com aqueles que, quase sempre, pensam que nada sabem, para que estes, transformando seu pensar que nada sabem em saber que pouco sabem, possam igualmente saber mais (FREIRE, 2013, p.25).

Corroborando com Freire, Tinoco e Giraldi (2019), sinalizam que a educação pode ser construída por diferentes meios e espaços, tanto no ambiente escolar - que é de extrema importância no processo de formação - como fora da escola, no meio familiar e cultural em que o sujeito está inserido; pois a educação é um processo constante que se dá por meio das interações pessoais, sociais e institucionais.

\section{METODOLOGIA}

A presente pesquisa foi desenvolvida em disciplina do Programa de Pós-Graduação em Enfermagem (PEN) da Universidade Federal de Santa Catarina (UFSC), intitulada "Promoção da Saúde no Processo de Viver Humano e Enfermagem". Foram sujeitos de pesquisa 12 pessoas, sendo 9 profissionais da saúde - enfermeiros - e três profissionais da rede Pública de Ensino - professores de Educação Básica.

\begin{tabular}{llllll}
\hline Hygeia Uberlândia - MG & Edição especial: X GeoSaude & Fev./2022 & p. 1-11 Página 6
\end{tabular}


O estudo foi realizado de acordo com os princípios éticos que constam na Resolução 466/2012 do Conselho Nacional de Saúde (CNS). A pesquisa foi aprovada pelo Comitê de Ética em Pesquisa com Seres Humanos da Universidade Federal de Santa Catarina, com Certificado de Apresentação para Apreciação Ética (CAAE) número 80121317.4.0000.0121. Para a garantia do anonimato, os nomes dos participantes foram substituídos por codinomes por eles aleatoriamente eleitos.

A metodologia consistiu na aplicação do Itinerário Freiriano: Círculo de Cultura, respeitando a Portaria n 343 de 17 de março de 2020 do Ministério da Educação que dispõe sobre a substituição das aulas presenciais por aulas em meios digitais enquanto durar a situação de pandemia do Novo Corona vírus - COVID-19. Tendo isto posto, utilizando-se de recursos midiáticos o encontro aconteceu via plataforma Google meet (link: https://meet.google.com/ifo-qqpt-gpt?authuser=2) e foi dividido em três momentos de dialogicidade e reflexão, conforme a proposta metodológica apresentada na figura 1: Temas Geradores, Codificação e Descodificação e Desvelamento Crítico. Segue subscrito a aplicabilidade da metodologia com as suas ponderações.

\section{RESULTADOS E DISCUSSÃO}

Os desdobramentos e resultados da pesquisa encontram-se desvelados em cada momento do processo. Estes, discorrem-se na sequência abaixo.

\section{Primeiro momento: Temas Geradores}

Para a investigação temática, inicialmente foi apresentado um vídeo como forma de sensibilização para fomentar o universo vocabular dos participantes, contendo imagens de vivência desses profissionais. O mesmo, pode ser acessado link: https://drive.google.com/drive/folders/1hATRbpCN1RmABaxFhARwUkkZWxaUpo12?usp=sharing.

A partir dessa sensibilização, os profissionais foram convidados a escrever duas palavras que expressavam problemas ou situações limite de seu cotidiano, ou seja, o início do processo dialógico. Para o registro dessas palavras, utilizou-se a plataforma https://www.mentimeter.com/, com a disposição do link https://www.menti.com/2vw3zmk8xx, onde foi construído simultaneamente pelos participantes, uma nuvem de palavras ou temas geradores da pesquisa. Como resultado desta prática, segue abaixo a figura 2 .

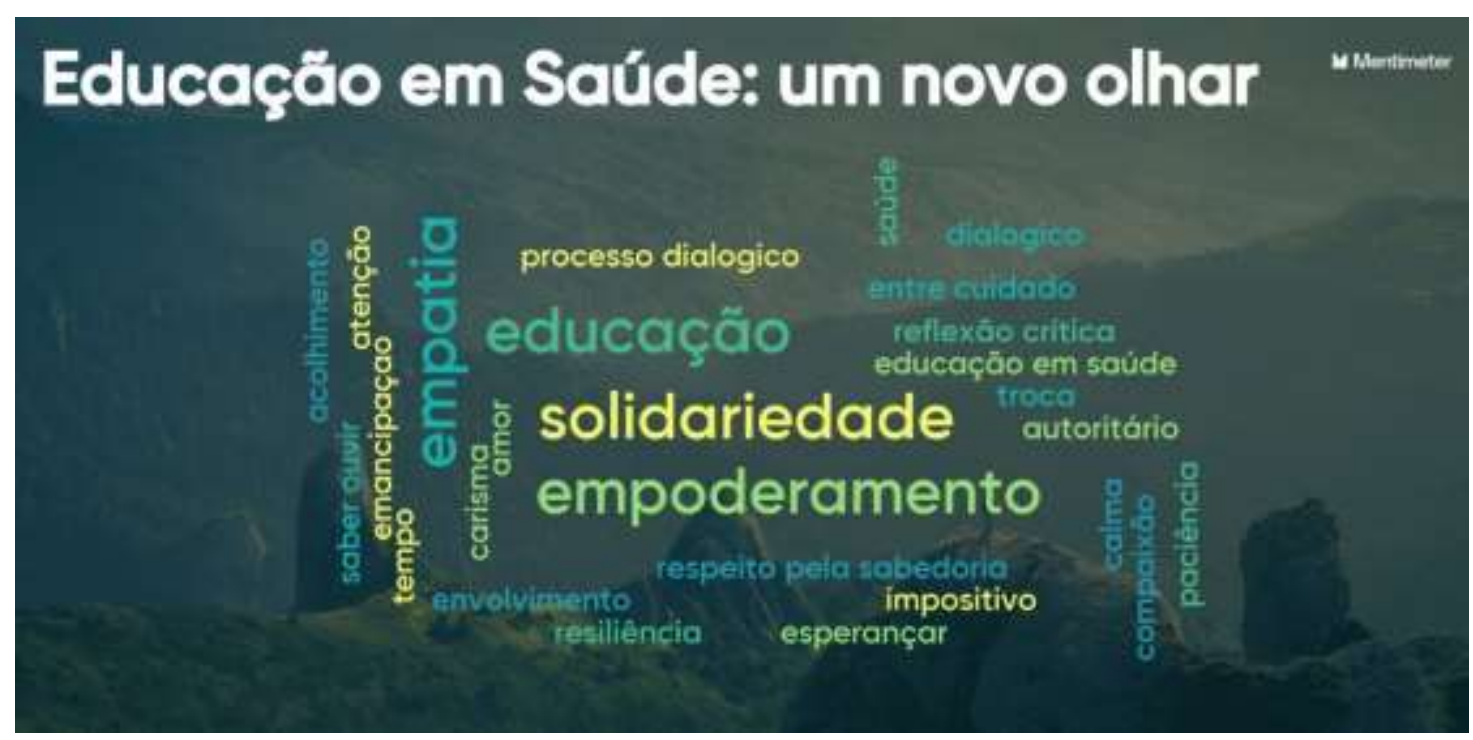

Fonte: Organizado pelos autores (2021).

Partindo da premissa que as palavras em destaque apareceram com maior frequência entre as respostas dos envolvidos, sinaliza-se que "Solidariedade; Empoderamento; Educação e Empatia"; são compreendidos como indicadores essenciais para o desenvolvimento da temática Educação em Saúde. Este resultado demonstra a necessidade do trabalho colaborativo, fruto da essência humana já abordada por Maturana (1985) em Teoria da cooperação. De acordo com o autor, "Tudo o que é dito

\begin{tabular}{llllll}
\hline Hygeia & Uberlândia - MG & Edição especial: X GeoSaude & Fev./2022 & p. 1-11 & Página 7
\end{tabular}


mostra que não existe, biologicamente falando, contradição entre o social e o individual. Ao contrário, o social e o individual são, de fato, inseparáveis" (MATURANA, 1985, p. 84).

Nesse contexto integrativo, Heidemann et al. (2017), em mesmo momento na construção de temas geradores com profissionais da saúde, em Círculo de cultura de Freire, ratificou também o aspecto colaborativo humano como abordagem primordial da ação humana, desvelando termos como: "acolhimento; ações comunitárias; relacionamento da equipe de saúde". Nesse sentido, a investigação dos temas geradores se concretiza pela utilização de um método conscientizador, permitindo apreender e inserir os homens num campo de pensamento crítico sobre o seu mundo.

Essa primeira etapa da educação como prática problematizadora se afirma na busca pela compreensão do mundo em suas relações com homens e mulheres evoluindo de uma realidade inerte, para um caminho em constante movimento, sendo possível o despertar para a consciência crítica (HEIDEMANN et al., 2017)

\section{Segundo momento: Codificação e Descodificação}

Após o início do processo educador-libertador, ponderando sobre cada tema gerador, a fase de codificação, possibilitou reconhecer o contexto concreto e gerar diferentes possibilidades de reflexões, sobre o tema "Saúde". Nesta fase problematizadora, os sujeitos de pesquisa foram indagados sobre implementações de políticas públicas que ocorreram ao longo do tempo em nosso país, no contexto SUS através de uma linha temporal que encontra-se disponível no link: https://padlet.com/isabelbohnvieira/mw4zd7pappbmewn1.

Dando segmento a atividade, a fim de propor um momento dialético para fase de descodificação, foi disposto uma apresentação no formato Power Point, (mesmo link do drive, apresentado no primeiro momento) com imagens de satélite, reportando a localização de Unidade Básica de Saúde, Escola de Rede Pública de Ensino e moradias inseridas em um território que encontra-se fragilizado social e economicamente. A partir dessa análise crítica, com situações reais de subsistência, os envolvidos foram estimulados e refletir sobre sua possível ação nesse contexto territorial.

Compreender o território como uma área de abrangência intersetorial e promotora de saúde, mesmo em meio as adversidades sociais, infere em superar o individualismo e voltar o olhar para as ações coletivas. Conforme Falkenberg (2014), práticas de educação em saúde são inerentes ao trabalho em saúde, mas muitas vezes estão relegadas a um segundo plano no planejamento, pois falta organização entre os setores para a execução das ações de cuidado.

Também, Barreto et al. (2019), afirma que as atividades educativas acabam arraigadas como segundo componente uma vez que as ações de caráter gerencial e o atendimento aos programas demandam tempo, gerando sobrecarga a sobreposição de atividades ao enfermeiro. Considerando a Atenção Primária de Saúde (APS) uma equipe multiprofissional, práticas de Educação em Saúde podem envolver toda a equipe,bem como os profissionais da Educação Básica, dirimindo assim, a responsabilidade de um único profissional. A prática dialógica entre os profissionais têm como finalidade a autonomia dos sujeitos, sendo a APS um ambiente com grande potencialidade para o desenvolvimento das ações intersetoriais, participação popular, e empoderamento individual e/ou coletivo (BARRETO et al. 2019).

\section{Terceiro momento: Desvelamento Crítico}

É nesse momento que os sujeitos de pesquisa, mediados pelo pesquisador, despertaram para possíveis transformações, vislumbrando diferentes olhares sobre a realidade o qual encontram-se inseridos. Nesta fase de tomada de consciência, todos os profissionais envolvidos na pesquisa foram estimulados a compartilhar as transformações percebidas durante o Círculo de Cultura e expressar essas ponderações através de registro em mural temático "Educação em Saúde". Este, pode ser acessado no link: https://padlet.com/isabelbohnvieira/df5p66i7ln3enc6m.

Dentre os relatos inseridos no mural temático destacam-se: "Educação em saúde é essencial, principalmente na escola, por possibilitar inclusive mudanças culturais importantes para a reconstrução de uma sociedade melhor"; "Ao ouvir a importância do diálogo em Freire, acredito na possibilidade de transformação dos opressores e oprimidos na sociedade". Ao perceber o processo da transformação proposta pelo Círculo de Cultura de Freire descrita nos relatos, os participantes experimentaram um processo de metamorfose, transmutando-se em parte da experiência vivenciada pelo coletivo, tendo a experiência vivenciada traduzida em verbalizações e revelada pelas histórias compartilhadas.

$\begin{array}{lllll}\text { Hygeia Uberlândia - MG } & \text { Edição especial: X GeoSaude } & \text { Fev./2022 } & \text { p. 1-11 } & \text { Página } 8\end{array}$


De acordo com Falkenberg (2014), metodologias de ensino-aprendizagem participativas e dialógicas promovem reflexão sobre a prática da Educação em Saúde e podem auxiliar na mudança de paradigmas. À vista dessa prática, configura-se no terceiro momento como (re)construção e (re)significação de espaços coletivos, concretos e legítimos, proposto à circulação da palavra.

\section{CONSIDERAÇÕES FINAIS}

O presente trabalho abordou a aplicação do Itinerário Freiriano como proposta dialógica intersetorial entre profissionais da saúde e educação. Foi notório o envolvimento dos participantes em todos os momentos da pesquisa, mesmo que remotamente devido ao contexto Pandêmico, mostrou-se possível e eficaz com uso de tecnologias aplicar a pesquisa participativa e promover a dialogicidade intersetorial resultando em aprendizagem significativa entre os envolvidos.

Salienta-se que, adentrar a intersetorialidade com a proposta de pesquisa participativa na temática "Educação em Saúde" permitiu promover a elucidação de conceitos até então desconhecidos entre os participantes. Fato este, sinalizado em segundo momento do círculo de cultura, com relatos dos profissionais da saúde em desconhecer a obrigatoriedade, presente em documento TCT's, do eixo temático saúde no currículo escolar, bem como os profissionais da educação desconhecerem os preceitos do PSE, quanto estratégia de integração e articulação permanente entre as equipes de saúde da família e a educação básica.

Por conseguinte, temas geradores suscitados como: "processo dialógico", "reflexão crítica", "empoderamento ou "esperançar", no primeiro momento da pesquisa, sinalizou que está intrínseco no processo de viver humano a necessidade de ponderar e agir com autonomia frente as situações as quais somos encorajados em nossa labuta diária. Dessa forma, alicerçar os conhecimentos de profissionais de diferentes áreas, aguerridos de documentos norteadores que coadunam para um mesmo objetivo quanto a formação de indivíduos na sua complexidade biológica, psicológica, cultural e social, ou seja, em sua integralidade de forma universal e equitativa, a educação em saúde se constrói no Brasil transformando vidas e promovendo saúde.

Atividades promotoras de saúde executadas com intencionalidades, de forma intersetorial e planejada, doravante utilização de recursos midiáticos assomados a intervenção prática e reflexiva, em diferentes dimensões geográficas de atuação, provirá a apropriação produtiva do conhecimento científico por notória autonomia e mudança de comportamentos entre os envolvidos.

É importante destacar que não se avaliou ou discutiu a dimensão espacial no dialogo na "Educação em Saúde" neste trabalho, por decisão dos pesquisadores, tendo em vista privilegiar a metodologia de Círculo de Cultura de Freire. Entretanto, compreender as mediações que condicionem a dialogicidade intersetorial, nos faz também refletir sobre os processos de aprendizagem que levam as intervenções promotoras de saúde aos diferentes grupos sociais. De toda forma, o desenvolvimento da pesquisa implicará também refletir a dimensão dos territórios de ação desses profissionais. Pois estes na mediação dos conhecimentos, buscando a integração das diferentes áreas de conhecimento com vistas a autonomia no conjunto das ciências da vida, implica reconhecer o território como forma indissociável a reprodução do trabalho e da dimensão histórica dos grupos socais. De fato, esta etapa futura mostrase como um desafio a ser dirimido.

\section{REFERÊNCIAS:}

ALBUQUERQUE, M. V. de et al. Desigualdades regionais na saúde: mudanças observadas no Brasil de 2000 a 2016. Ciência \& Saúde Coletiva, v. 22, p. 1055-1064, 2017. https://doi.org/10.1590/1413$\underline{81232017224.26862016}$

BARRETO, A. C. O. et al. Percepção da equipe multiprofissional da Atenção Primária sobre educação em saúde. Revista Brasileira de Enfermagem, v. 72, p. 266-273, 2019.

BECKER, R. M.; HEIDEMANN, I. T. S. B. Promoção da saúde no cuidado às pessoas com doença crônica não transmissível: revisão integrativa. Texto Contexto Enferm [Internet]. 2020. Disponível em: https://dx.doi.org/10.1590/1980-265X-TCE-2018-0250. . Acesso em: 05 mar. 2021. https://doi.org/10.1590/1980-265x-tce-2018-0250

BRASIL. Ministério da Saúde (MS). Secretaria Executiva Sistema Único de Saúde (SUS): princípios e conquistas. Brasília: Ministério da Saúde, 2000. 44p. Disponível em: https://bvsms.saude.gov.br/bvs/publicacoes/sus_principios.pdf. Acesso em 06 mar. 2021.

\begin{tabular}{llllll}
\hline Hygeia Uberlândia - MG & Edição especial: X GeoSaude & Fev./2022 & p. 1-11 Página 9
\end{tabular}


BRASIL . Ministério da Saúde (MS). Secretaria de Gestão do Trabalho e da Educação na Saúde. Departamento de Gestão e da Regulação do Trabalho em Saúde. Câmara de Regulação do Trabalho em Saúde. Brasília: MS; 2006.

BRASIL. Decreto Presidencial no 6.286, de 5 de dezembro de 2007. Institui o Programa Saúde na Escola - PSE, e dá outras providências. Diário Oficial da União 2007; 6 dez. Disponível em: http://www.planalto.gov.br/ccivil_03/_ato2007-

2010/2007/decreto/d6286.htm\#: :text=DECRETA\%3A,promo\%C3\%A7\%C3\%A30\%20e\%20aten\%C3 \%A7\%C3\%A30\%20\%C3\%A0\%20sa\%C3\%BAde. Acesso em: 10 mar. 2021.

BRASIL. Ministério da Educação. Secretaria de Educação Básica. Base Nacional Comum Curricular Terceira versão. Brasília, DF: MEC/SEB, 2017. Disponível em: $<$ http://basenacionalcomum.mec.gov.br> Acesso em 05 mar. 2021.

BRASIL. Ministério da Educação. Guia de Implementação dos Temas contemporâneos transversais na Base Nacional Comum Curricular: propostas de práticas de implementação. MEC, Brasília, DF, 2018. Disponível em: http://basenacionalcomum.mec.gov.br/images/implementacao/guia_pratico_temas_contemporaneos.p df. Acesso: 05 mar. 2021.

BRASIL. Ministério da Educação. Gabinete do Ministro. Portaria no 343, de 17 de março de 2020. Dispõe sobre a substituição das aulas presenciais por aulas em meios digitais enquanto durar a situação de pandemia do Novo Coronavírus - COVID-19. Diário Oficial da União, Brasília, DF, ed. 53, 18
mar. 2020.
Seção $\quad 01$
p. 39
Disponível
em:

http://www.planalto.gov.br/ccivil_03/Portaria/PRT/Portaria\%20n\%C2\%BA\%20343-20-

mec.htm\#: :text=PORTARIA\%20N\%C2\%BA\%20343\%2C\%20DE\%2017,que\%20lhe\%20confere\%20 \%\%20art. Acesso em: 24 abr. 2021

CANGUILHEM, G. O normal e o patológico. Rio de Janeiro: Forense Universitária, 2012.

CAPONI, S. A saúde como abertura ao risco. In: Promoção da saúde: conceitos, reflexões, tendências. 2009. p. 59-81. https://doi.org/10.5020/18061230.2008.p81

CARVALHO, F. F. B. de. A saúde vai à escola: a promoção da saúde em práticas pedagógicas. Physis: Revista de Saúde Coletiva, v. 25, p. 1207-1227, 2015. https://doi.org/10.1590/S010373312015000400009

COSTA, M. A. R. et al. Itinerário de pesquisa Paulo Freire contribuição no campo de investigação em enfermagem. Rev. enferm. UFPE on line, p. 546-553, 2018.Disponívem em: https://doi.org/10.5205/1981-8963-v12i2a109935p546-553-2018. Acesso em 04 abr. 2021. https://doi.org/10.5205/1981-8963-v12i2a109935p546-553-2018

CUNHA, R. R, BACKES, V. M, HEIDEMANN, I. T. S. B. Desvelamento crítico da pessoa estomizada: em ação o programa de educação permanente em saúde. Acta Paul Enferm. 2012; 25(2):296-301. https://doi.org/10.1590/S0103-21002012000200022

FALKENBERG, M. B. et al. Educação em saúde e educação na saúde: conceitos e implicações para a saúde coletiva. Ciência \& Saúde Coletiva, v. 19, p. 847-852, 2014. https://doi.org/10.1590/141381232014193.01572013

FREIRE, P. Pedagogia do oprimido. 9. ed. Rio de Janeiro: Paz e Terra, 1981.

FREIRE, P. Pedagogia da autonomia: saberes necessários à prática educativa. São Paulo (SP): Paz e Terra; 2011. 6. Freire P. Pedagogia do Oprimido. 54th ed. Rio de Janeiro (RJ): Paz e Terra; 2013.

GARDNER, H. et al. Inteligências múltiplas. Minnesota Center for Arts Education, 1992.

HEIDEMANN, I. B. S. H, BOEHS, A. E, WOSNY, A. M, STULP, K. P. Incorporação teórico-conceitual e metodológica do educador Paulo Freire na pesquisa. Rev Bras Enferm. 2010; 63(3):416-20. https://doi.org/10.1590/S0034-71672010000300011

HEIDEMANN, I. T. S. B.; WOSNY, A. D. M.; BOEHS, A. E. Promoção da saúde de mães adolescentes: investigação temática de Freire na Saúde da Família. Rev Rene, Fortaleza, jul/set; 12(3):582-88, 2011. Disponível em: http://www.periodicos.ufc.br/rene/article/view/4292. Acesso em: 05 mar. 2021.

HEIDEMANN, I. T. S. B, WOSNY, A. D. M., BOEHS, A. E. Promoção da saúde na atenção básica: estudo baseado no método de Paulo Freire. Cien Saude Colet [Internet]. 2014; 19(8):3553-9.

Hygeia Uberlândia - MG $\quad$ Edição especial: X GeoSaude $\quad$ Fev./2022 p. 1-11 Página 10


Disponível em: http://www.scielo.br/pdf/csc/v19n8/1413-8123- csc-19-08-03553.pdf. Acesso em: 05 mar. 2021. https://doi.org/10.1590/1413-81232014198.11342013

HEIDEMANN, I. T. S. B., et al. Reflexões sobre o itinerário de pesquisa de Paulo Freire: contribuições para a saúde. Texto \& Contexto-Enfermagem, v. 26, n. 4, 2017. https://doi.org/10.1590/0104$\underline{07072017000680017}$

MATURANA, H. Biología del fenómeno social in Maturana, Humberto (1985). Desde la Biología a la Psicología. 3. ed. Santiago de Chile: Editorial Universitária, 1996.

RODRIGUES, L. Z.; PEREIRA, B.; MOHR, A. O documento "Proposta para Base Nacional Comum da Formação de Professores da Educação Básica"(BNCFP): dez razões para temer e contestar a BNCFP. Revista Brasileira de Pesquisa em Educação em Ciências, p. 1-39, 2020. https://doi.org/10.28976/1984-2686rbpec2020u139

SOUZA, R. R. Ministério da Saúde. O sistema público de saúde brasileiro. Seminário Internacional Tendências e Desafios dos Sistemas de Saúde nas Américas. Brasília: Ministério da Saúde, 2002. 45p. Disponível em: https://bvsms.saude.gov.br/bvs/publicacoes/sistema_saude.pdf. Acesso em: 06 mar. 2021.

TINOCO, R. A. L.; GIRALDI, P. M. Educação não formal: potencialidades e limitações na formação do futuro professor de ciências e biologia. EDUCA-Revista Multidisciplinar em Educação, v. 6, n. 16, p. 190-209, 2019. https://doi.org/10.26568/2359-2087.2019.4292. Acesso em: 10 mar. 2021. https://doi.org/10.26568/2359-2087.2019.4292 